\title{
More Evidence on the Performance of Merger Simulations
}

\author{
Matthew C. Weinberg
}

December 30, 2010

Government antitrust agencies must predict the price effects of proposed mergers and challenge those predicted to raise prices. Merger simulation, models of oligopoly combined with demand estimates, are routinely used to simulate the effects of potential mergers (see Werden and Froeb (2006) for a survey). Merger simulation addresses the key question regulators must answer: would a potential merger reduce consumer welfare? However, they require strong assumptions on the nature of competition both before and after the merger occurs, the shape of demand and marginal cost functions, as well as the statistical assumptions necessary to consistently estimate demand. Given these strong assumptions and the substantial resources devoted to antitrust review, it is important to evaluate the accuracy of simulation methodology. This paper adds to a small literature that evaluates merger simulation by comparing predicted price effects to retrospective estimates of the price effects of a merger (eg Peters (2006) and Weinberg and Hosken (2009)).

This paper uses the acquisition of Tambrands by Proctor and Gamble to provide more evidence on the performance of merger simulations. Using only pre-merger data, two simple demand systems are estimated under several commonly used identification assumptions and these estimates are used to simulate the merger using a model of Bertrand competition. Next, using both pre- and post-merger data, I directly estimate the price effects of the mergers using standard techniques from the program evaluation literature following Ashenfelter and Hosken (Forthcoming). If the assumptions necessary to simulate the merger hold, the simulated price effects should be close to the directly estimated price effects.

The direct estimates imply that the merger increased prices. These estimates are calculated by comparing the change in the price of the merging firms products to the change in price of similar private label products. The difference in difference estimates imply that after the merger the price of Always pads increased by 8 percent relative 
to private label pads and the price of Tampax tampons increased by 5 percent relative to private label tampons. If private label prices increased in response to the merger, these estimates are a lower bound on the true effect of the merger on the merging firms' products. The simulations give much smaller price increases-the prices of both Always pads and Tampax tampons were predicted to increase by about 1 percent. The direct estimates lie outside a 95 percent confidence interval around the simulated price changes. Thus, the simulations substantially under-predicted the price effects of a merger that was retrospectively estimated to be anticompetitive.

\section{Merger Background and Data}

In July of 1997, Proctor and Gamble (P\&G) purchased Tambrands for 1.85 billion dollars. The acquisition made $\mathrm{P} \& \mathrm{G}$ the leading seller of both sanitary pads (Always) and tampons (Tampax), but did not increase concentration within a market for tampons or pads. While tampons and feminine hygiene pads are different types of products, they are functionally similar and if they were important substitutes it is likely that the merger would reduce consumer surplus. According to press reports, the Department of Justice reviewed the case but did not take any enforcement action ${ }^{1}$.

The data used in this study are scanner data from the food channel of Information Resources Incorporated (IRI). The data are weekly total revenue and unit sales by week, region, and Universal Product Code (UPC). IRI's food channel covers 64 regions and the data spans the period from October 27, 1996 until January 2, 2000. Prior to the merger, there were 7 firms in the market producing 4 branded tampons and 4 branded feminine hygiene pads along with private label brands for both tampons and pads.

There are three typical variations of feminine hygiene pads: thin, medium, and heavy. Each brand uses the same brand name for each type of pad, and each variation is sold at the same price and put on sale at the same time. For this reason, I follow Ashenfelter and Hosken (Forthcoming) and create a single price by dividing total weekly sales by volume for each brand. The reader is referred to that paper for more details on the construction of the dataset.

\footnotetext{
${ }^{1}$ New York Times, June 7, 1997.
} 


\section{Demand Systems and Merger Simulation}

The first step in simulating a merger is demand estimation. I consider two simple models of demand: logit and nested logit. While logit demand places strong restrictions on elasticities, it remains popular in antitrust due to the quickness with which it can be calculated and its relatively limited data requirements. In order to allow more flexible elasticities, I next estimate a nested-logit demand model. Nested logit has been used in merger simulation by Peters (2006) and Lucarelli, Prince and Simon (2009), amongst others. The available brands are partitioned into 3 nests: tampons, feminine hygiene pads, and the outside good. The nested logit estimating equation is given by:

$$
\begin{aligned}
& \ln v_{i n t}-\ln v_{0 n t}=\sigma \ln v_{i \mid k}^{-}-\alpha p_{i n t} \\
& +x_{i n t} \beta+\gamma_{n}+\alpha_{t}+\epsilon_{i n t}
\end{aligned}
$$

where $v_{\text {int }}$ is the volume share of product $i$ in region $n$ during week $t$ and good 0 is the outside option ${ }^{2} . x_{i n t}$ are product characteristics, and $\gamma_{n}$ and $\alpha_{t}$ are region and week fixed effects. $v_{i \mid k}^{-}$is the volume share of product $i$ within its nest. The parameter $\sigma$ ranges between 0 and 1 . When $\sigma$ is closer to one there is a higher chance that a consumer will switch to another product in the same nest given a price increase. As $\sigma$ becomes close to zero the nested logit collapses to the simple logit model.

The merger is simulated as follows: let $\Delta$ be the matrix with element $\Delta_{i j}=\frac{\partial v_{i}}{\partial p_{j}}$ if the same firm owns both brands $i$ and $j$ and 0 otherwise. Then the first-order conditions can be written as $v+\Delta_{\text {pre }}(p-m c)=0$ and the marginal costs are given by $m c=\Delta_{p r e}^{-1} v+p$. I follow Hausman, Leonard and Zona (1994) and Knittel and Metaxoglou (2008) by approximating the post-merger equilibrium by $p_{\text {post }}=m c-\Delta_{\text {post }}^{-1} * v$.

\section{Results}

The direct estimates of P\&G's acquisition of Tambrands were estimated in two ways. First, the price effects were estimated with a difference in difference estimator using similar private label products as a comparison group, similar to Ashenfelter and Hosken

\footnotetext{
${ }^{2} \mathrm{~A}$ measure of market potential is necessary in order to calculate the outside share in both the logit and nested logit model. I assume that women are equal to half the population in each IRI region, and each woman can consume up to six feminine hygiene products per day for 6 days per month.
} 
(Forthcoming). The estimating equation is given by:

$$
\begin{aligned}
& \ln \left(p_{i t}\right)=\alpha_{i n}+\eta_{t}+ \\
& +\delta * \text { PostMerger }_{t} * \text { Branded }_{i}+\epsilon_{i t}
\end{aligned}
$$

where here $\alpha_{i n}$ are region/brand fixed effects, $\eta_{t}$ are weekly time effects common to both branded and private label products, PostMerger Po $_{t}$ is a dummy variable equal to one after the merger occurred, and Branded $i$ is a dummy variable equal to one if the product is not private label. This equation was estimated separately with OLS for the two types of feminine hygiene products: Tampax and private label tampons and Always and private label pads. Standard errors were clustered by region. $\delta$ is the parameter of interest, and measures the growth in branded products relative to private label products after the merger. ${ }^{3}$ The second approach drops the comparison group and calculates the merger effect as the time difference in average log prices, conditional on month dummies and region/brand fixed effects. Following Ashenfelter and Hosken (Forthcoming), I drop data three months before and after the merger to avoid timing issues.

Figure 1 Here

Figure 2 Here

Figures 1 and 2 present average log prices for Tampax and private label tampons and Always and private label pads, respectively. There is a clear increase in the prices of Always pads relative to private label pads and Tampax tampons relative to private label tampons after the merger. There are two potential pitfalls to the difference in difference strategy. First, anything that effects the merging firms' products differently from private label products over time will lead to bias. However, in the pre-merger period, there is no apparent differential trend in the prices of the branded and private label products. The second potential pitfall is a response in private label pricing to the merger. If this is the case, the simple Bertrand model suggests that the difference in difference estimate will understate the price effects.

The results from the difference in difference and time difference estimates are in columns 1 and 2 of Table $1\left(100^{*} \delta\right.$ is reported). The difference in difference estimates in column 1 imply that the merger increased the price of Always Pads by 8 percent and

\footnotetext{
${ }^{3}$ This specification is slightly different from Ashenfelter and Hosken. While I allow for common week effects, they constrain the time effects to be the same before and after the merger while controlling for common month effects.
} 
Tampax tampons by 5 percent. Column 2 reports the before and after comparison. The price effects are slightly smaller, implying that the price of private label products actually fell after the merger.

\section{Table 1 Here}

The logit and nested logit demand models were estimated in several different ways. To start, the logit model was estimated with OLS. Brand fixed effects were included to control for product characteristics. Throughout, standard errors were clustered by region. Evaluated separately in each market, all own-price elasticities were less than one in magnitude ${ }^{4}$.

I next estimate both the logit and nested logit demand models using two different sets of instruments that are feasible in typical scanner data sets. First, I follow Nevo (2000) amongst others by using prices in other regions. For logit demand there is only one potentially endogenous regressor, price, so I use the average price in all other regions. The first stage partial F-stat is 324, far above standards for instrument relevance. However, the IV estimate of the coefficient on price is smaller than the OLS estimate, and implies ownprice elasticities less than one in magnitude. The nested logit model has two regressors that are likely endogenous: price as in the logit model and the log volume share conditional on nest. The nested logit model was estimated using two-stage least squares with prices in the 4 furthest regions as 4 separate instruments. Again, the instruments were relevant, but $\sigma$, the measure of intragroup correlation, was estimated to be much larger than one and the coefficient on price was estimated to be positive.

Finally, I estimate the nested logit with two-stage least squares using brand fixed effects as instruments, another approach common in the literature (eg Lucarelli, Prince and Simon (2009)). This is similar to using non-price characteristics as instruments. The coefficient on the nested logit term, $v_{\bar{i} \mid k}$, was estimated to be 1.09. This is inconsistent with consumer optimization, but suggests that the coefficient is near one and indirect utility is highly correlated within a nest. In order to generate elasticities consistent with the underlying model, I restrict $\sigma$ to be equal to .95 and then re-estimate the model again using brand dummies as instruments for price. This yields estimates that imply own-price elasticities to be less than negative one and usable in a merger simulation.

I simulate the merger with the two sets of demand estimates that are consistent with optimizing behavior: logit estimated by OLS and nested logit estimated by two stage least

\footnotetext{
${ }^{4}$ Elasticities are available upon request
} 
squares using brand dummies as instruments. The results are in columns 3 and 4 of Table 1. $95 \%$ confidence intervals were calculated by taking 1000 draws from the asymptotic distribution of the demand estimate, simulating the merger for each draw, and taking quantiles of the simulated percentage price changes. For both demand models, the merger was expected to yield small price increases of about 1 percent, significantly smaller than the direct estimates using pre and post-merger data.

\section{Conclusions}

I find that two simple merger simulations significantly underestimated the price effects of P\&G's acquisition of Tambrands. The results of this study, however, are limited to the oligopoly and demand models considered. Two commonly assumed demand models were estimated: nested logit and logit. While both are easily estimated and frequently used in estimating demand in consumer goods industries, it would be interesting to see if other demand models yield better results. However, even for the simple demand systems considered in this paper, standard instrumental variable strategies available in scanner datasets often yielded elasticity matrices inconsistent with the underlying theory of merger simulations. 


\section{References}

Ashenfelter, Orley C. and Daniel S. Hosken, "The Effect of Mergers on Consumer Prices: Evidence from Five Selected Case Studies," Journal of Law and Economics, Forthcoming.

Hausman, Jerry A., Gregory K. Leonard, and J. Douglas Zona, "Competitive Analysis with Differentiated Products," Annales D'Economie et de Statistique, 1994, 34 (1), 159-180.

Knittel, C.R. and K. Metaxoglou, "Estimation of Random Coefficient Demand Models: Challenges, Difficulties and Warnings," Technical Report, NBER Working Paper 2008 .

Lucarelli, Claudio, Jeffrey T. Prince, and Kosali Simon, "The Welfare Impact of Reducing Choice in Medicare Part D: A Comparison of Two Regulation Strategies," Working Papers 2010-14, Indiana University, Kelley School of Business, Department of Business Economics and Public Policy October 2009.

Nevo, Aviv, "Mergers with Differentiated Products: The Case of the Ready-to-Eat Cereal Industry," The RAND Journal of Economics, 2000, 31 (3), 395-421.

Peters, Craig, "Evaluating the Performance of Merger Simulations: Evidence from the U.S. Airline Industry," Journal of Law and Economics, 2006, 49, 627-649.

Weinberg, Matthew C. and Daniel Hosken, "Using Mergers to Test a Model of Oligopoly," Working Paper, Bryn Mawr College 2009.

Werden, Gregory J. and Luke M. Froeb, "Unilateral Competitive Effects of Horizontal Mergers," in Paolo Buccirossi, ed., Handbook of Antitrust Economics, MIT Press, 2006. 
Table 1: Estimated and Simulated Percentage Price Effects for Merging Firms' Products

\begin{tabular}{l|cccc}
\hline \hline & \multicolumn{2}{|c}{ Estimated Price Changes } & \multicolumn{2}{c}{ Simulated Price Changes } \\
\cline { 5 - 5 } Products & $\begin{array}{c}\text { Difference in } \\
\text { Differences }\end{array}$ & Time Difference & Logit & $\begin{array}{c}\text { Nested Logit } \\
\text { IV }\end{array}$ \\
\hline \multirow{3}{*}{ Always Pad } & & & & \\
& 7.83 & 5.22 & 0.77 & 1.14 \\
Tampax Tampon & $(0.57)$ & $(0.47)$ & $(0.66,0.93)$ & $(0.99,1.34)$ \\
& 5.33 & 4.33 & 0.86 & 1.27 \\
& $(0.92)$ & $(0.64)$ & $(0.74,1.04)$ & $(1.10,1.50)$ \\
\hline
\end{tabular}

Notes: Authors' own calculations on IRI data. Standard errors clustered on region are in parentheses below difference in difference and difference estimates. 95 percent confidence intervals in parentheses under simulated price changes. Confidence intervals were constructed through drawing from asymptotic distribution of demand parameters, simulating the merger for each draw, and taking quantiles of the empirical distribution. Variance-covariance matrices of demand estimators are clustered by region.

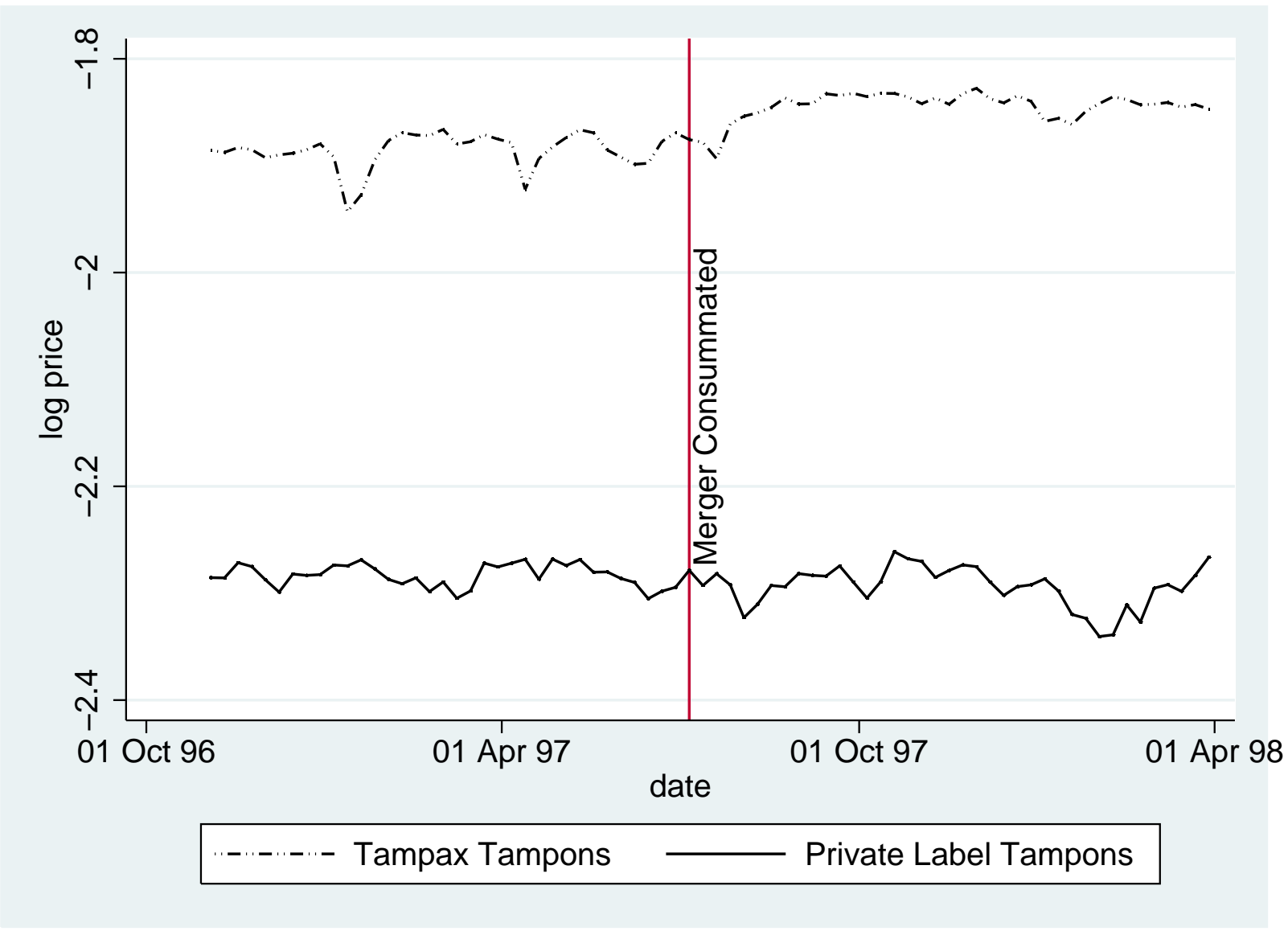

Notes: Average log price of Tampax tampons and private label tampons across 64 IRI regions. 


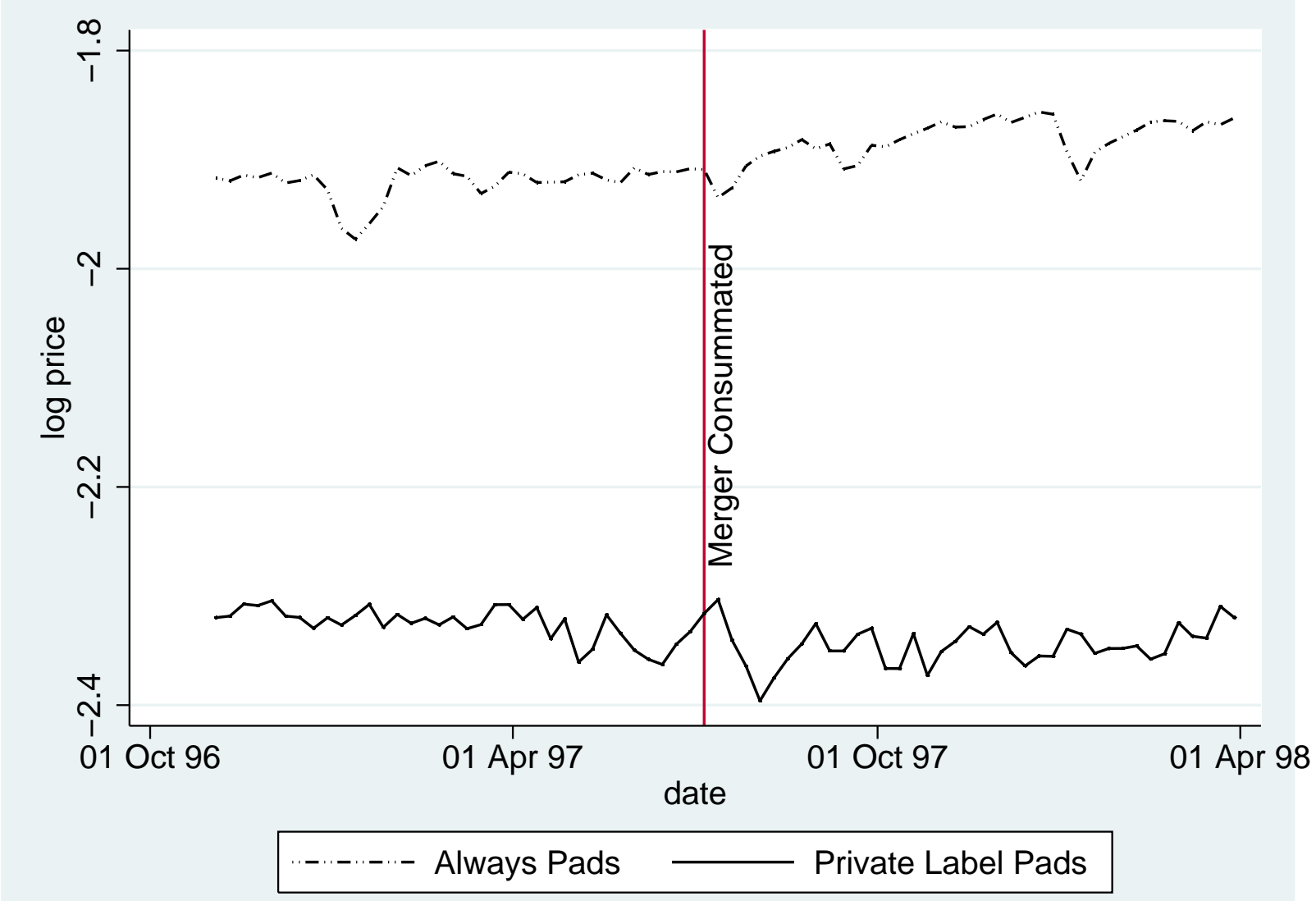

Notes: Average log price of Always pads and private label pads across 64 IRI regions. 